\title{
What to say about cold fusion
}

Public interest in recent excitements is to be welcomed, especially if it does not turn to anger when attempts to replicate the observation of cold fusion fail - the most probable outcome.

Fleischmann and Pons have done at least one great service for the common cause: they have kindled public curiosity in science to a degree unknown since the Apollo landings on the Moon. In the past few weeks, people thought by those about them to have a few scraps of inside knowledge have been quizzed about the smallest details of the experiments at the University of Utah - those first described in the Wall Street Journal and the Financial Times on 23 March and at a press conference at Salt Lake City later that same day. The social phenomenon is all the more remarkable because of the wide distribution of those who have a general understanding of nuclear fusion and of the reasons why its practical application would be important.

These impromptu conversations seem generally to be remarkably goodhumoured. Those who want to know more, and who in particular ask "Do you think it's true?", seem not too much annoyed by the prospect of continued suspense. It is remarkable that so many people are willing to accept that experimental observations, and the inferences drawn from them, acquire validity only by replication. Has what used to be called "the scientific method" now become widely understood?

If so, much of the credit should go to the daily press, which has risen superbly to the challenge of cold fusion. The two financial newspapers that broke the news on 23 March did so in cautious language, making it plain that cold fusion was not then a proven reality, let alone a commercial source of limitless energy. Other daily newspapers have joined in with commendable zeal and sobriety. Inevitably, the US daily press, with its resources and selfdiscipline, has done best, but newspapers such as the London Daily Telegraph, with no great tradition in the field of science reporting, have been magnificent. Reporters have given full and coherent accounts of meetings as far apart as Sicily and Texas, have canvassed opinions with care and have also faithfully reflected the good humour of these hectic weeks.

The good humour may not persist if the experiments cannot be replicated but there are some grounds for optimism. Part of the reason why so many people are so interested seems to be the general delight that a couple of people in widely separated universities have used their own money to pull off a trick on which governments have lavished huge sums of money in the past 30 years, so far without result. So people may well be indulgent if the attempts to replicate cold fusion on the scale described by Fleischmann and Pons prove failures. "It was a brave venture", they may say, "What a pity it did not succeed!"

That would be the best outcome. It is also, of course, possible that the general reaction to the failure of attempts at replication will be more sour. The scientific community's reputation is vulnerable in several respects, not the least of which is that neither the Utah group nor the Brigham Young group (whose account of its work appears on page 737 , this issue) had, before seeking publication, carried out the rudimentary control experiment of running their electrolytic cells with ordinary rather than heavy water.

A close friend who is a Soviet biologist, on the telephone from the United States last week, was indignant at this neglect. $\mathrm{He}$ is correct. How is this astonishing oversight to be explained to students repeatedly being drilled in the need that control experiments should be as conspicuous in the design of an investigation as those believed to display the phenomenon under study? And how should the neglect be explained to the world at large?

There is no convincing explanation, only extenuating circumstances. Selfimposed secrecy has evidently hampered the investigators, understandably buoyed up by their belief that they had discovered a remarkable new phenomenon and fearful that too much talk about it would give other bigger battalions a chance to steal a march on them. Yet it is unthinkable that, if the authors had felt able from the outset to stand in front of routine laboratory colloquia and give a full account of their work, the question "Have you tried it with ordinary water?" would not have been raised. This glaring lapse from accepted practice is another casualty of people's need to be first with reports of discovery and with the patents that follow.

More subtle doubts perplexing those seeking to replicate the experiments would have been exorcised in the same process. The Brigham Young group, for example, clearly explains how it has been necessary to estimate the number of neutrons emitted from its electrolytic cells by subtracting from its observations of neutrons the background measurements, but Dr John M. Carpenter (one of the referees of the article by Jones et al.) explains on page 711 that the background may fluctuate with time, which argues for the need for contemporaneous controls. Sadly, the neutron monitor is a special device, of which there is only one copy....

The Fleischmann and Pons experiments raise bigger questions, if only because the scale of the phenomenon they report is so much greater. Both groups report the detection of neutrons, but the Utah group (J. Electroanalyt. Chem. 261, 301; 1989) requires that there should be $10^{12}$ fusion reactions a second (within an order of magnitude in either direction) to account for the rate at which heat is produced, while the Brigham Young group is talking of one fusion reaction every 100 seconds or so. But the Utah group has not yet dealt with the natural question whether the observed energy output is energy stored in the palladium electrodes during the preparation of the cell. Records of cell voltage and current for the full duration of each run would go some way to settle the question, but have not been produced.

So are the extenuating circumstances sufficient to avoid the conviction of the scientific community for irresponsibility? No doubt the general opinion will depend on the outcome of attempts at replication, but the community might wish that its reputation did not hang on such a narrow thread, especially because the likelihood of replication fades as the days go by.

So robust scepticism is the only wise view. There may be something in the Brigham Young phenomenon, but that requires careful confirmation. The Utah phenomenon is literally unsupported by the evidence, could be an artefact and, given its improbability, is most likely to be one.

Luckily, there are a few blessings to count. Theoreticians have zealously recalculated the fusion rate between deuterons in a molecule (now reduced by 10 orders of magnitude) and have shown that the fusion rate between protons and deuterons, against naive expectation, is likely to be six orders of magnitude greater still - but still no more than $10^{-5 t}$ per molecule of HD per second. A week or so ago, ingenious schemes for bringing bare hydrogen nuclei more closely together in the electron sea of a palladium lattice seemed to offer an escape from scepticism. But not for long, even if it is plain that metal hydrides are an even more interesting field of research than had been thought.

John Maddox 